ПРОБЛЕМА ХАРАКТЕРА И НАПРАВЛЕНИЯ КУЛЬТУРНО-ИСТОРИЧЕСКОГО ДВИЖЕНИЯ

DOI: 10.31618/ESU.2413-9335.2020.2.71.586

Алишерова Чолпон Базарбековна

кандидат философских наук, доиент кафедры

Государственного языка общественных наук,

Кыргызский государственный университет геологии, горного дела и освоения природных ресрусов

Кыргызская Республика, г.Бишкек

\title{
THE PROBLEM OF THE NATURE AND DIRECTION OF THE CULTURAL-HISTORICAL MOVEMENT.
}

\author{
Alisherova Cholpon Bazarbekovna \\ Candidate of Philosophy, Associate Professor \\ of the Departament of the State \\ Language and Social Sciences, \\ Kyrgyz State University of Geology, \\ Mining and Natural Resources Development \\ Kyrgyz Republic, Bishkek
}

\begin{abstract}
АННОТАЦИЯ
Освещено решение проблемы характера и направления культурно-исторического движения. Рассмотрены разные варианты, концепции. Затронуты культурологические концепции Ф.Шиллера, Гердера и других. Подробно раскрываются взгляды на логику развития культурно-исторического процесса представителей советской культуры Выделены типы эволюционных концепций культуры такие как, однолинейная эволюция есть рассмотрение истории культуры как последовательного развития различных систем (религии, нравов, хозяйства и др.) с выделением в нем общих стадий (Э. Тайлор, Дж. Фрейзер, JI. Леви-Брюль).

Вторым типом эволюционного понимания логики культурно исторической динамики является теория универсальной эволюции. Суть ее состоит в признании самобытности развития различных этнокультур, отрицания общих стадий и общей схемы движения, но цель и смысл его понимается сторонниками ее различно. Сторонниками это теории являются Н. Я. Данилевский, А. Тойнби, В. Соловьев, К. Ясперс, Б. Малиновский и др. В их концепциях заключена идея культурной эволюции человечества, идущего разными путями к некоторому единству, идея полифоничности мировой культуры и признания равноценности всех ее составляющих.

Третий тип эволюционного учения о культуре - теорий многолинейной эволюции. Во взглядах представителей этой теории (Р.Бенедикта, М. Херсковица и др.) утверждается полимерность социокультурного пространства, самоценность разных типов и моделей культуры.

Таким образом, в статье даны основные концепции, предлагающие оригинальные решения одной из важных проблем в философии культуры - проблемы логики культурно-исторического движения. Сейчас, в период бурного социального ритма развития производственной и внепроизводственной деятельности прогнозирование изменений в пространстве становится особенно важным. Учет многочисленных технических и социальных последствий научно-технической революции выдвигают требования, связанные с пространственным прогнозом.

\section{ANNOTATION}

This article highlights the solution to the problem of the nature and direction of the cultural and historical movement. Different options, concepts are considered. The cultural concepts of Schiller, Herder and others are fected. View on the logic of the development of the cultural and historical process of representation of Soviet culture are revealed in detail. The types of evolutionary concepts of culture, such as single-line volition, are a consideration of the history of culture as the sequential development of various systems (religion, morals, economy e.t.c.) with the identification of general stages in it (E.Taylor, J.Fraser, L. Levy-Bruhl). The second type of evolutionary understanding of the logic of cultural-historical dynamics is the theory of universal evolution. Its essence is to recognize the identity of the development of various ethnic cultures, the denzal of the general stages and the general scheme of movement, but the purpose and meaning, of it is understood by its supporters differently Supporters of this theory are N.Ya Danilevsky, A.Toynbee, V.Solovyov, K. Jaspers, B. Malinvsky and others. Their concepts include the idea of the cultural evolution of mankind, going in different ways to some unity, the idea of polyphonic world culture and recognition the equivalence of all its components.

The third type of evolutionary doctrine of culture is theories of multilinear evolution. The views of the representatives of this theory (R.Benedict, M. Herskovitz etc.) affirm the polymerization of the sociocultural space, the intrinsic value of different types and models of culture.

Thus, the article gives the basic concepts that offer original solutions to one of the important problems in the philosophy of culture the problems of the logic of the cultural-historical movement. Now, in a period of rapid social rhythm of the development of production and non-production activities, the forecasting of changes in space
\end{abstract}


is becoming especially important/ Taking into account the numerous technical and social consequences of the scientific and technological revolution put forward requirements related to spatial forecasting

Ключевые слова: пространство, культура, киберпространство, планета, цивилизация, глобализация, искусственная среда, прогресс, концепция, культурология.

Key words: space, culture, cyberspace, planet, civilization, globalization, artificial environment, progress, concept, culturology.

Решение этой проблемы имеет разные варианты, разные концепции.

В эпоху Просвещения идея креационизма была вытеснена теорией исторического прогресса, согласно которой развитие культуры рассматривалось как триумфальное шествие разума, как поступательное

движение в разумном освоении человеком мира и совершенствовании самого человека как субъекта этой деятельности. Но уже Ж.-Ж. Руссо высказал сомнение в культурном могуществе разума, утверждая, что развитие культуры противоречиво и неоднозначно.

В культурологических концепциях Ф. Шиллера и И. Гердера также присутствует неуверенность в абсолютном характере культурного прогресса.

Воззрения XIX века на культурноисторический процесс как на поступательное движение, в ходе которого меняются и совершенствуются формы свойств человека (культура), а на каждую его стадию как на преходящую и подготавливающую новую, более совершенную, завершили гегелевская философия духовной истории, контовская теория стадиального развития познания и теория социокультурного прогресса К. Маркса, повлиявшая, в значительной мере, на взгляды советской культурологии.

Однако в советской культурологии имели место и другие взгляды на логику культурноисторического процесса, отличающиеся различным подходом к культуре.

Так, например, в понимании В.М. Межуева проблема культуры раскрывается как проблема изменения самого человека, в понятие культуры входит только то, что способствует культурному становлению человека. Подобное понимание культуры содержится и в работах А.И. Арнольдова, Л.С. Злобина, Л.Н. Когана и др.

C иных позиций рассматривают теорию культурного прогресса В.С. Библер, Л.Н. Гумилев. Так, например, позиция Л. Н. Гумилева в вопросе логики развития культуры близка к теории цивилизационных циклов А.

Тойнби. Культурологическая теория М.К. Петрова основана на концепции многолинейной эволюции.

Таким образом, в советской марксистской философии также развивались взгляды, отвергавшие теорию прогресса применительно к динамике культуры.

На Западе теория социокультурного прогресса нашла отражение в ряде технократических концепций, например, JI. Мемфорда и Х.Шельски . Эволюционная трактовка культурноисторического процесса шире представлена в культурологии XIX - XX веков. Так, можно выделить три типа эволюционных концепций культуры.

Однолинейная эволюция есть рассмотрение истории культуры как последовательного развития различных систем (религии, нравов, хозяйства и др.) с выделением в нем общих стадий (Э. Тайлор, Дж. Фрейзер, JI. Леви-Брюль).

Вторым типом эволюционного понимания логики культурно исторической динамики является теория универсальной эволюции. Суть ее состоит в признании самобытности развития различных этнокультур, отрицания общих стадий и общей схемы движения, но цель и смысл его понимается сторонниками еe различно. Сторонниками это теории являются Н. Я. Данилевский, А. Тойнби, В. Соловьев, К. Ясперс, Б. Малиновский и др. [1] .В их концепциях заключена идея культурной эволюции человечества, идущего разными путями к некоторому единству, идея полифоничности мировой культуры и признания равноценности всех ее составляющих.

Третий тип эволюционного учения о культуре - теорий многолинейной эволюции. Во взглядах представителей этой теории (Р.Бенедикта, М. Херсковица и др.) утверждается полимерность социокультурного пространства, самоценность разных типов и моделей культуры.[2].

Во второй половине XX века сформировался новый взгляд на культурно -исторический процесс. Так, А. Вебер разделил этот процесс на «цивилизационный», выражающийся в поступательном развитии науки и техники, «социальный» - прогресс в хозяйственной и политической жизни и на культуру - сферу душевно-духовных объективаций (искусство, религия, философия). Вебер считал, что развитие культуры в истории носит характер изменения, просто движения, у которого нет закономерностей и в процессе истории формируются и сменяют друг друга замкнутые культуры.[3].

Вопрос о необходимости изменения парадигмы культурно- исторического мышления остро поставил О. Шпенглер в своей книге «Закат Европы». Шпенглер отрицает эволюцию человечества и его культуры, так как рассматривает человечество как единую органическую систему, биологический вид, качественное изменение которого есть перерождение. Поэтому у Шпенглера локальные культуры умирают, а история не имеет цели.[4].

Во второй половине XX века в культурологии все большее признание получает идея синхронного существования различных исторических типов культуры. В частности, П. Сорокин, выделив три основных типа культуры, утверждал, что они не 
только сменяют друг друга, но могут сосуществовать в качестве доминирующей и побочной в рамках одной социокультурной системы. Культурно-историческое движение, по Сорокину, носит круговой характер, три универсальных типа культуры периодически сменяют друг друга и неизменно воспроизводят присущие им черты. [5].

Кризис самосознания европейской культуры привел к появлению новых взглядов на характер культурно-исторического движения.

Известный нидерландский историк и культуролог Й Хайзинга, оценивая духовную ситуацию своего времени (30-е годы), пришел к выводу, что «движение культуры должно содержать возможность и обращения, и возвращения, а именно в том случае, когда это касается признания или нового обретения вечных ценностей...» [6].

Р. Гвардини вообще не использует понятий «развитие», «прогресс» применительно к истории культуры. Культурно -исторический прогресс для Гвардини это - «изменение», «перестройка», «возникновение» и «исчезновение», «обретение» и «потери». Культурно-исторический процесс, согласно Гвардини, это изменение человека, способа его существования, осознания им себя в мире. Понимание культурной эволюции как модификации человека в истории получает все большее признание. Человечество в XX веке осознало тот факт, что социокультурное движение противоречиво, что расцвет и прогресс одних способностей и свойств человека сопровождается угнетением и деградацией других, развитие одних сторон социокультурной реальности происходит за счет регресса других.

В поиске новых ориентиров утвердилось признание разнонаправленности и разнохарактерности движения культур, плюрализма пространственно- временных культурных континуумов, синхронного существования различных типов культуры.

Несмотря на огромное количество теорий, вопрос о логике культурно-исторического процесса остается открытым.

Таким образом, обобщая результаты философских изысканий в области культурологии XX века, можно сделать следующие выводы:

1. Законы динамики культуры можно охарактеризовать не как эволюционные, а как модификационные: не развитие, а изменение человека в истории с потерями и приобретениями, с прогрессом одних аспектов и деградацией других.

2. Характер исторического движения культуры не является «постоянным», он может быть циклическим, прогрессивным, принимать вид многолинейной эволюции, в определенные исторические периоды в разных социокультурных регионах могут осуществляться разные типы движения культуры.

3 . Степень сходства и различия этнокультур также является непостоянной и зависит от множества факторов, среди которых тип культурно-исторического движения, характер взаимодействия этнокультур, социальноэкологические условия.

Интересной представляется точка зрения кандидата философских наук Т.В. Казаровой на логику культурно-исторического движения как на вероятностную, виртуальную. [7]. Виртуальность культурно-исторического процесса она раскрывает следующим образом:

В ш '«определенное состояние культуры, некий исторический и

- этнический ее тип является не единственно, а наиболее возможным

- $\quad$ при определенных(пространственновременных,

- психофизиологических, социальноэкологических и др.) условиях;

- у виртуального движения нет постоянного направления, оно складывается под давлением синтетической причины, целой системы факторов и периодически меняется;

- при всех известных параметрах и факторах, детерминирующих изменение культуры, всегда есть фактор «Х», поэтому перспективу движения точно предсказать невозможно;

- виртуальность движения не исключает стабильность связей системы, в данном случае человечества, поэтому «границей» движения социокультурной реальности являются родовые (универсальные) свойства и признаки человека;

- каждое конкретно- историческое состояние культуры (исторический тип) есть не стадия или ступень, а вариант. Поэтому о мировой культуре и ее истории можно говорить, как о проигрывании или развертывании, осуществлении вариантов человека»[8].

Итак, таковы на сегодняшний день основные концепции, предлагающие оригинальные решения одной из важных проблем в философии культуры проблемы логики культурно-исторического движения. Сейчас, в период бурного социального ритма развития производственной и внепроизводственной деятельности прогнозирование изменений в пространстве становится особенно важным. Учет многочисленных технических и социальных последствий научно-технической революции выдвигают требования, связанные с пространственным прогнозом.

\section{Литература:}

1.Петров М. К. Язык, знак, культура. - М.: Наука, 1991. - С. 7.

2.Наука о культуре: итоги и перспективы. - М., 1995. - Вып. 6. - С. 5.

3.Казарова Т.В. Проблема логики культурноисторического движения: варианты решения //Наука о Наука о культуре: итоги и перспективы. М., 1995. - Вып. 6. - С. 5.

4.Казарова Т.В. Проблема логики культурноисторического движения: варианты решения // Наука о культуре: итоги и перспективы. - М., 1995. 
- Вып. 6. - С. 9.

5.Шпенглер О. Закат Европы. - М.: Мысль, 1993. - С. 151.

6.Хейзинга Й. Homo jdenz. - М.: Прогресс, 1992. - С. 18.

7.Гвардини Р. Конец нового времени // Вопросы философии. - 1990. - № 4. - С. 19.

8.Казарова Т.В. Проблема логики культурно- исторического движения: варианты решения // Наука о культуре: итоги и перспективы. - М., 1995. - Вып. 6. - С. 9.

9.Казарова Т.В. Проблема логики культурноисторического движения: варианты решения // Наука о культуре: итоги и перспективы. - М., 1995. - Вып. 6. - G. 9. 